Disponível em:

http://editora.unoesc.edu.br/index.php/race

Race, Joaçaba, v. 15, n. 3, p. 1007-1034, set./dez. 2016

\title{
A IMAGEM PROFISSIONAL: UM ESTUDO SOBRE O FARMACÊUTICO
}

Professional image: a study about the pharmacist

Claudiney Luis Ferreira

E-mail: claudiney@solucoesfarmaceuticas.com.br Mestre em Administração pelo Centro Universitário UNA; Especialista em Gestão Estratégia de Negócios pela Universidade Federal de Minas Gerais; Diretor (Vice-Presidente) do Conselho Regional de Farmácia do Estado de Minas Gerais.

\section{Luiz Rodrigo Cunha Moura}

E-mail: luizrcmoura@gmail.com

Doutor e Mestre em Administração pela Universidade Federal de Minas Gerais; Professor Adjunto do Mestrado Profissional em Administração do Centro Universitário UNA. Endereço para contato: Rua dos Guajajaras, 175, Centro, 30180-100, Belo Horizonte, Minas Gerais, Brasil.

\section{Gustavo Quiroga Souki}

E-mail: gustavo.souki@prof.una.br

Doutor e Mestre em Administração pela Universidade Federal de Lavras; Professor Adjunto do Mestrado Profissional em Administração do Centro Universitário - UNA.

Artigo recebido em 24 de maio de 2015. Aceito em 16 de maio de 2016. 


\section{Resumo}

O objetivo neste trabalho foi identificar a percepção da imagem do farmacêutico, a qual foi subdivida em quatro dimensões: cognitiva, funcional, simbólica e emocional, baseadas nos modelos de Lindqvist (1974) e Stern, Zinkhan e Jaju (2001). Fez-se uma pesquisa exploratória por meio de entrevistas com 23 stakeholders (médicos, enfermeiros, fonoaudiólogo, fisioterapeuta, terapeuta ocupacional, discentes e docentes de Farmácia, farmacêuticos, usuários, entre outros) relacionados à profissão de farmacêutico. Os resultados indicam que para a dimensão funcional não há uma imagem específica do farmacêutico quanto aos aspectos tangíveis, pois a inseparabilidade exerce maior relevância na prestação de serviços. Para a dimensão cognitiva, os resultados apontam que não existe uma percepção clara de em que consiste a profissão e nem de suas atribuições. Na dimensão emocional a imagem do farmacêutico diz respeito às emoções evocadas antes, durante e após a prestação de um serviço. A dimensão simbólica mostrou que o farmacêutico tem significados que são representações assistencialistas e que remetem ao profissional como fonte confiável de informação. Os resultados obtidos nesse estudo podem ser empregados como norteadores para futuras ações estratégicas pelos conselhos regionais de farmácia de cada unidade federativa do Brasil e, principalmente, do Conselho Federal de Farmácia para um melhor posicionamento da imagem do profissional farmacêutico no mercado, podendo gerar maior satisfação no exercício da atividade pelo farmacêutico e uma possível valorização desse profissional para a sociedade. Ao final, faz-se uma análise comparativa entre a imagem do farmacêutico e as imagens de outros profissionais.

Palavras-chave: Imagem. Imagem profissional. Farmacêutico. Dimensões da imagem. Profissional de saúde.

\section{Abstract}

The objective in this work was to identify the Pharmacist image perception, which was subdivided into four dimensions: cognitive, functional, symbolic and emotional, based on Lindqvist's (1974) and Stern, Zinkhan and Jaju's (2001) models. There was an exploratory research through interviews with 23 stakeholders (physicians, nurses, speech therapist, physical therapist, occupational therapist, Pharmacy students and teachers, Pharmacists, users, etc.) related to the Pharmacist profession. The results indicate that for the functional dimension there is a specific image pharmacist about the tangible aspects because the inseparability exerts greater relevance in the services provision. For the cognitive dimension, the results indicate that there is not a clear perception of what the profession is nor of its duties. In the emotional dimension of the Pharmacist image comes to emotions evoked before, during and after the service provision. The symbolic dimension showed that the Pharmacist has meanings that are welfare representations and that refer to the professional as a reliable information source. The results can be used as guidelines for future strategic actions by regional pharmacy councils in each federal unit in Brazil and especially of the Federal Pharmacy Council for better 
positioning of the pharmaceutical professional image in the market and it can generate better satisfaction in the activity performance by the Pharmacist and a possible valorization of this professional to society. At the end, is held it a comparative analysis between the pharmacist's image and other professions als' ones.

Keywords: Image. Professional image. Pharmacist. Image dimensions. Healthcare professional.

\section{INTRODUÇÃO}

A imagem contempla um conjunto de significados pelos quais se chega a avaliar um objeto e, por meio do qual, as pessoas o descrevem, recordam e se relacionam. A imagem é a consequência da interação de ideias, crenças, sentimentos e impressões formadas pelas pessoas (consumidores) sobre determinado objeto (KUNSCH, 2003). Diversos autores vêm defendendo a importância que as imagens exercem na vida das pessoas e dos consumidores (FINN; LOUVIERE, 1996; GOSS, 2010; MOSCOVICI, 2000). As pesquisas sobre imagem têm como objetivo relacionar as imagens às marcas, produtos/serviços e organizações (BARICH; KOTLER, 1991; DOBNI; ZINKHAN, 1990; STERN; ZINKHAN; JAJU, 2001). Em relação especificamente ao estudo da imagem dos profissionais, pode-se citar Aquino, Aquino, Teixeira e Andrade (2012), Mendes (2008) e Grasseli (2007) que estudaram, respectivamente, a imagem dos funcionários públicos, psicólogos e arquitetos.

Construir e conservar uma boa imagem não pode estabelecer um fim em si mesmo. Para cultivar uma imagem apropriada e maximizar seu valor intrínseco, a imagem deve ser o reflexo de um bom produto, de uma boa empresa, de uma boa pessoa ou de um bom trabalho.

Nos serviços de saúde e, em particular, na farmácia, a verificação da imagem que os diversos grupos de pessoas que, de alguma maneira, interagem com a profissão, constitui-se em importante marco para o seu direcionamento estratégico. A imagem é capaz de influenciar e direcionar o comportamento da sociedade em geral (AREOSA; CARAPINHEIRO, 2008).

O farmacêutico precisa adaptar suas funções de acordo com a realidade. Ele deve possuir, além de conhecimentos específicos sobre o uso de medicamentos e acompanhamento farmacoterapêutico, conhecimentos e habilidades administrativas, pois as farmácias são empresas e é necessário desenvolver, ainda, uma visão comercial para determinar um plano de negócio compatível, que garanta a sua ratificação no segmento em que atua (FRANCESCHET, 2003). Por outro lado, farmacêuticos sugerem que o reconhecimento e a valorização da profissão não se apresentam atualmente 
compatíveis com a magnitude da sua relevância. Acredita-se que diversos fatores podem estar favorecendo a esse problema. Entre eles, pode-se destacar:

a) o baixo conhecimento que a sociedade possui em relação às atribuições e ao papel do profissional farmacêutico (FARINA; ROMANO-LIEBER, 2009);

b) farmacêuticos podem não possuir conhecimentos necessários sobre marketing de serviços, o que pode gerar uma baixa qualidade na prestação dos serviços aos clientes e, desvalorização profissional (ITALIANI, 2006);

c) a carência de uma estratégia consistente na projeção da imagem da profissão de farmacêutico;

d) a inadequação de estratégias pelo Conselho Federal e conselhos regionais de farmácia de posicionamento da profissão em razão da amplitude de atuação profissional.

Assim, o objetivo deste trabalho é identificar qual é a percepção dos usuários e dos profissionais de farmácia em relação à imagem do farmacêutico.

Para analisar a imagem atual do farmacêutico é imprescindível que seja identificada a imagem sob a percepção dos farmacêuticos e dos stakeholders, principalmente, pelos usuários dos serviços desse profissional. Dessa forma, é possível verificar se existe uma dissonância entre a imagem percebida e a imagem projetada dessa profissão.

Diante desse levantamento, podem-se obter subsídios que auxiliem no gerenciamento da imagem da profissão de farmacêutico, de forma a ampliar o seu reconhecimento e a percepção de valor pelos clientes. Dessa forma, é provável que exista uma possível lacuna na imagem do profissional farmacêutico que pode contribuir para o baixo reconhecimento e para a valorização da profissão para a sociedade.

Foram realizadas pesquisas nas seguintes bases de dados: Scielo, EbscoHost, Cengage, banco de teses da Capes, SourceOECD, Proquest e Google Scholar, utilizando como palavras-chave: imagem e farmacêutico, pharmaceutical and image. Não foram encontrados estudos que buscaram avaliar a imagem do profissional farmacêutico. Dessa forma, em princípio, o trabalho pode ser considerado inovador.

Em termos teóricos, considerando o aspecto de pioneirismo do tema relacionado à profissão do farmacêutico, é possível ressaltar que existe uma lacuna sobre o conhecimento da imagem do farmacêutico e que este trabalho pode contribuir para o preenchimento de parte dessa lacuna. Há de se considerar, também, a possível uti- 
lização das informações advindas desta pesquisa, para a mensuração da imagem de outras profissões.

Existem no mercado farmacêutico brasileiro 398 indústrias farmacêuticas nacionais e multinacionais registradas. O Brasil ocupa lugar de destaque no cenário farmacêutico mundial, por ser um dos países que mais cresce, da mesma forma que outros emergentes como a China e a Índia. O maior mercado do mundo é o norte-americano, seguido pelos japonês, alemão e francês. Ainda, o mercado farmacêutico brasileiro ocupa a décima colocação no mercado mundial, colaborando com 2,3\% das vendas totais de medicamentos do mundo (SCATENA, 2012). Conforme dados do Conselho Federal de Farmácia (2013), existem hoje no Brasil 416 cursos de graduação em Farmácia, e o número de farmácias chega a 66,5 mil.

\section{REFERENCIAL TEÓRICO}

\subsection{CONCEITOS E FUNDAMENTOS DA IMAGEM}

A imagem é geralmente concebida como o resultado de uma operação pela qual os sinais emitidos por uma unidade de comercialização são recebidos por um receptor e organizados em uma percepção mental da unidade de envio. No entanto, o foco da pesquisa pode variar dependendo do aspecto da imagem em estudo. Pode-se referir a uma entidade, como uma empresa, produto/marca ou loja, mas também se pode referir a uma entidade psicológica, como um padrão de crenças e sentimentos no pensamento do consumidor estimulado por associações com o mundo real, ou pode-se referir a mensagens publicitárias PYR ou de relações públicas. Dessa forma, o termo refere-se a três domínios diferentes da realidade: o mundo externo, a mente do consumidor e os intermediários entre esses dois (STERN; ZINKHAN; JAJU, 2001).

Conforme Aaker (1997), a intenção e a organização lógica de determinado conjunto de associações podem suscitar percepções que comporão uma imagem. Essa imagem pode ou não refletir a realidade. Desse distanciamento entre imagem e realidade conclui-se que uma imagem pode ser formada a partir de premissas falsas, pois mesmo que não corresponda à verdade, ela pode ser entendida pelas pessoas como tal.

A imagem também pode ser definida pela impressão que permanece na mente das pessoas, tendo esta uma extensa área de aplicação, como: impressão da profissão, da empresa, do produto, de um candidato, entre outras (DICHTER, 1985; JOLY, 2003). 
Para Tavares (1998), a imagem pode ser entendida como a do objeto em foco, produto, marca, empresa, setor ou pessoa. As imagens são classificadas em seis categorias principais: imagem corporativa (categoria mais ampla e abrangente da imagem); imagem da classe de produto (extrapola na amplitude a imagem da empresa); imagem de marketing (inclui os elementos do marketing da empresa); imagem de marca (dimensão mais restrita das várias categorias consideradas); imagem de produto (forma como as pessoas observam uma categoria particular de produto) e imagem do usuário da marca.

Roberts (2003) alegou que a construção de uma imagem profissional é a chave para o estabelecimento de uma boa reputação entre os diversos constituintes da força de trabalho do século XXI.

A imagem profissional se refere às percepções que os colegas e clientes possuem a respeito da competência, do caráter e da compostura. Uma pessoa que constrói a imagem de um profissional competente é vista pelos colegas, superiores, subordinados e clientes como sendo capaz de ir ao encontro das exigências técnicas e sociais de suas atividades (IBARRA, 1999; ROBERTS, 2003).

Vough et al. (2013) desenvolveram um modelo de discrepâncias da imagem percebida pelos clientes sobre a imagem profissional. Foram encontradas diferenças entre o que os profissionais percebem sobre sua profissão e o que os outros percebem. Os profissionais acreditam que as percepções de seus papéis pelos clientes podem desvalorizar sua profissão e gerar falsas expectativas dos resultados que poderiam ser alcançados.

\subsection{DIMENSÕES DA IMAGEM}

Segundo May (1974), a imagem é formada por várias dimensões, que podem ser classificadas em tangíveis ou intangíveis, mensuráveis ou não mensuráveis, mutáveis ou imutáveis. Os fatores tangíveis são distinguidos pelas qualidades físicas e mensuráveis do serviço ou produto, em oposição às características subjetivas, que são de difícil mensuração e que caracterizam os fatores intangíveis (LINDQVIST, 1974; MAY, 1974; REYNOLDS; GUTMAN, 1984; STERN; ZINKHAN; JAJU, 2001).

Assim, Dobni e Zinkhan (1990), Johnson e Zinkhan (1990), Stern, Zinkhan e Jaju (2001), De Toni, Milan e Schuler (2004), Milan, De Toni e Barazetti (2005) e De Toni (2009) reforçam a existência de diferentes dimensões no estudo sobre as imagens e propuseram as seguintes dimensões da imagem: funcional, simbólica, emocional e cognitiva. 
Tais dimensões da imagem foram utilizadas por De Toni, Milan e Schuler (2004) para a avaliação da imagem de produtos (vinhos e telefone celular), para a profissão de Arquitetura (GRASSELI, 2007), para a profissão de Fisioterapia (AMORIM, 2009), para a profissão de Psicologia (MENDES, 2008), para a imagem do programa de orientação e proteção ao consumidor (MACHADO, 2010), para a imagem do intercâmbio de cursos de idioma (VICTER, 2009) e para a imagem de um shopping center (GASPARIN, 2011).

A dimensão funcional é constituída por elementos tangíveis é traduzida por uma série de atributos físicos que são percebidos e analisados pelos clientes durante a prestação de serviços, como, por exemplo, localização, tamanho, arquitetura, aparência das pessoas que fazem parte da equipe, equipamentos disponíveis, as instalações físicas, cor, design, valor, cheiro, entre outras, que perpassam a funcionalidade do objeto analisado pelo consumidor. Divulga a qualidade e os benefícios de determinado objeto por meio dos seus elementos tangíveis (STERN; ZINKHAN; JAJU, 2001).

Como a dimensão funcional é fundamentalmente racional, está contida nela a percepção das informações que o objeto fornece. Tais características expressam a serventia do produto, do serviço e/ou da marca, deixando os consumidores atribuírem um valor aos serviços prestados. Essa dimensão constitui-se das características físicas percebidas e avaliadas pelos consumidores acerca do objeto (DE TONI; MILAN; SCHULER, 2005).

A dimensão cognitiva é formada por construções mentais sobre o serviço e o objeto, usadas pelos consumidores para uma avaliação dessas imagens. As crenças e o conhecimento prévio do indivíduo em relação ao produto ou serviço, influenciam diretamente na construção dessas imagens. É como um construto mental, racional e lógico que os consumidores utilizam para avaliar um objeto, pois o sistema cognitivo cria redes de conhecimento que organizam e conectam vários tipos de informação, atribuindo significado a ele.

Esse construto mental é inteiramente influenciado pelas crenças e pelo conhecimento prévio do consumidor em relação ao objeto. Nessa dimensão se posiciona o conjunto de ideias, percepções, impressões, sentimentos, julgamentos e atitudes que o consumidor tem sobre esse determinado objeto (DICHTER, 1985; DOBNI; ZINKHAN, 1990; GARDNER; LEVY, 1955; MARTINEAU, 1958; REYNOLDS, 1965).

A dimensão cognitiva resulta da relação entre a imagem como um conjunto de atributos extrínsecos no mundo real e a imagem como uma construção mental desenvolvida pelo consumidor. Dessa forma, a imagem é tratada tanto como uma entidade externa quanto como uma construção mental. Quando tratada como uma 
construção mental é desenvolvido um processamento cognitivo que inclui ideias, sentimentos, atitudes, construções mentais ou expectativas (STERN; ZINKHAN; JAJU, 2001). Tal nível de percepção vai gerar os atributos racionais de determinado objeto, que estarão disponíveis ao pensamento para atingir todas as suas operações básicas de análise, síntese e inferência. Essa dimensão é influenciada por fatores motivacionais e emocionais potencialmente conflitantes, muitos dos quais podem estar em ação ao mesmo tempo (DE TONI et al., 2011).

A dimensão emocional está relacionada aos sentimentos, emoções e estados de ânimo que o consumidor possui em relação a determinado objeto; experiências internas estas que o motivam a organizar as imagens e a guiá-lo em suas ações. Sobrepõe-se à imagem em formação uma informação de caráter qualitativo, avaliativo, despertando humores, interesses que uma pessoa possui em relação ao serviço, ao produto e à marca (DE TONI; MILAN; SCHULER, 2005).

Essa dimensão faz reverência ao estado afetivo, positivo ou negativo, que os consumidores agregam ao objeto. Ressalta-se que esse estado de emoções positivas e negativas está ligado ao comportamento e à satisfação, ou insatisfação, do consumidor com o objeto (REYNOLDS; GUTMAN, 1984).

A dimensão simbólica está relacionada à significação que o objeto tem para o consumidor. Lida com o objeto de forma abstrata, pois o que as pessoas compram tem um significado pessoal, hedônico e social, além de suas funções utilitárias. Os serviços são avaliados pelo que representam ou significam para o indivíduo. Essa dimensão realça o valor da pessoa aos seus próprios olhos (autoestima) e aos olhos de terceiros (status), ou seja, reforça os valores, sentimentos e objetivos do indivíduo e serve como um dispositivo de entendimento entre o consumidor e o seu símbolo de referência (DOBNI; ZINKHAN, 1990; LEVY, 1959; MARTINEAU, 1958; STERN; ZINKHAN; JAJU, 2001).

A imagem refere-se a um conjunto de objetos, ações, palavras, imagens e/ou comportamentos humanos complexos que servem como substitutos para outras ideias ou sentimentos. As definições nessa dimensão são simples, descritivas e associativas para elaborar conceitos complexos e sinais semióticos (LEVY, 1959). O consumidor entende, nessa dimensão, o valor do objeto enquanto símbolo, a feição de algo para si mesmo ou para os demais componentes do seu grupo social (DE TONI et al., 2011).

\section{METODOLOGIA}

A pesquisa tem uma abordagem exploratória caracterizada como aquelas que têm o propósito de desenvolver e esclarecer conceitos e ideias, com foco para a for- 
mulação de problemas mais sucintos ou hipóteses pesquisáveis em estudos posteriores (GIL, 2010).

A pesquisa exploratória tem como principal finalidade possibilitar uma melhor compreensão do problema afrontado pelo pesquisador, permitindo resolver o problema com maior precisão, identificar cursos alternativos de ação, desenvolver hipóteses, isolar variáveis e relações-chave para análise futura, obter critérios para desenvolver uma abordagem do problema ou propor prioridades para pesquisas posteriores. Segundo Vergara (2013), os estudos exploratórios são realizados em áreas em que o conhecimento não é sistematizado e pouco acumulado.

Assim, foram realizadas entrevistas abertas, com abordagens pessoais e diretas, aplicadas separadamente, com o intuito de se conhecer melhor a opinião dos stakeholders diretamente envolvidos com a construção e análise da imagem do profissional farmacêutico, para levantar quais variáveis relacionadas com as dimensões da imagem são projetadas pelo profissional farmacêutico e que são percebidas como importantes pela sociedade e por ele próprio.

Cabe destacar que os participantes das entrevistas foram selecionados por conveniência. Entende-se, portanto, que o critério de amostragem utilizado nessa fase apresentará um caráter não probabilístico (MALHOTRA, 2011). Considerando que o interesse da pesquisa é o de explorar o problema com maior precisão, podendo gerar, ainda, como resultados o desenvolvimento de hipóteses e o conhecimento de variáveis para uma possível pesquisa quantitativa, a utilização da metodologia qualitativa torna-se adequada.

Foram entrevistadas as seguintes categorias de stakeholders:

a) Discentes Curso Farmácia: representam os futuros farmacêuticos e estão no processo de formação da imagem profissional, que irá refletirá no profissional futuramente. Podem relatar falhas ou sucessos em seu processo de formação com seleção de indivíduos matriculados no início do curso e próximos à colação de grau;

b) docentes Curso de Farmácia: são os indivíduos que corroboram diretamente na formação da imagem da profissão de farmacêutico;

c) coordenadores do Curso de Farmácia: são os responsáveis pela seleção e treinamento dos docentes e elaboração das ementas e diretrizes curriculares;

d) farmacêuticos: importantes para identificar algumas variáveis da imagem percebida por esses profissionais; 
e) representante do Conselho Regional de Farmácia: trata-se de uma autarquia que se responsabiliza pelo registro e fiscalização profissional e, também, participa da elaboração de normas e resoluções que contribuem para a formação da imagem do farmacêutico;

f) profissionais da área da Saúde: são os profissionais mais próximos do farmacêutico e que contribuem para a formação da imagem desses profissionais. Serão entrevistados nesse grupo: médico, enfermeiro, fisioterapeuta, fonoaudiólogo e terapeuta ocupacional;

g) usuários: são os indivíduos que recebem os serviços prestados pelos farmacêuticos e que serão objetos de interesse neste estudo para avaliarem a percepção da imagem do profissional farmacêutico. São considerados, em princípio, como a sociedade em geral, excluindo-se os participantes dos grupos anteriores. A sua importância deriva do fato de poderem assim como os grupos anteriores - criar, alterar ou manter o "senso comum” sobre a imagem do farmacêutico percebida na sociedade em geral.

Após definição dos grupos, foram entrevistados quatro médicos, um enfermeiro, um fonoaudiólogo, um fisioterapeuta, um terapeuta ocupacional, três discentes de farmácia, dois representantes do Conselho Regional de Farmácia de Minas Gerais, dois Farmacêuticos, um docente de farmácia, dois coordenadores de curso de Farmácia e cinco usuários.

As questões que compõem o roteiro de entrevista foram baseadas no referencial teórico e também considerando-se o objetivo geral. Esse roteiro foi dividido em cinco partes; a primeira contém questões relacionadas aos aspectos gerais (avaliar o relacionamento do entrevistado com o profissional farmacêutico), e das demais partes foram segmentadas para cada uma das dimensões da imagem (simbólica, funcional, cognitiva e emocional), sendo compostas por questões específicas para cada uma dessas dimensões. 
Quadro 1 - Resumo das questões que compõem o roteiro de entrevista

\begin{tabular}{|c|c|}
\hline Categoria & Temas abordados no roteiro de entrevista \\
\hline Geral & $\begin{array}{l}\text { Pontos positivos e negativos da experiência do entrevistado com os farmacêuti- } \\
\text { cos; as coisas que vêm à mente quando ouve a palavra “farmacêutico”; quais são } \\
\text { as funções do farmacêutico; indicação ou não do trabalho do farmacêutico para } \\
\text { parentes ou amigos; pontos fortes e fracos da profissão de farmacêutico; como } \\
\text { descreve a profissão de farmacêutico. }\end{array}$ \\
\hline Funcional & $\begin{array}{l}\text { Como descreve o farmacêutico; como imagina que seja o farmacêutico; signifi- } \\
\text { cado que o farmacêutico representa; como identifica quem é o farmacêutico; os } \\
\text { benefícios e malefícios que a atuação do farmacêutico gera para o entrevistado; } \\
\text { como avalia a qualidade do trabalho do profissional; vantagens e/ou desvantagens } \\
\text { da atuação do farmacêutico. }\end{array}$ \\
\hline Emocional & $\begin{array}{l}\text { Os sentimentos que vêm à mente do entrevistado quando ouve a palavra “farma- } \\
\text { cêutico”; que sentimentos tem quando vai à farmácia e encontra o farmacêutico; } \\
\text { o que oferece mais prazer quando vai à farmácia; o que o deixa mais feliz/infeliz } \\
\text { quando vai à farmácia; emoções positivas e/ou negativas que os farmacêutico } \\
\text { despertam nos clientes; como é o relacionamento entre o farmacêutico e o clien- } \\
\text { te; aspectos emocionais podem interferir nessa relação; emoções positivas e-ou } \\
\text { negativas que se sente quando é atendido por um farmacêutico. }\end{array}$ \\
\hline Cognitivo & $\begin{array}{l}\text { Principais atividades do farmacêutico; as atividades que o farmacêutico está } \\
\text { habilitado a exercer; o que o farmacêutico realmente faz; o que ele deve fazer e/ } \\
\text { ou não fazer; como seria um bom farmacêutico. }\end{array}$ \\
\hline Simbólico & $\begin{array}{l}\text { Descrição da pessoa que utiliza o trabalho de um farmacêutico ao invés de se } \\
\text { automedicar; o que a pessoa está buscando quando procura os serviços de um } \\
\text { farmacêutico; o que o trabalho do farmacêutico pode representar para os clientes; } \\
\text { as pessoas procuram um farmacêutico para terem mais segurança para utilizar } \\
\text { os medicamentos ou por conveniência; diferenças das percepções de homens e } \\
\text { mulheres em relação ao farmacêutico; constrangimento de homens e mulheres } \\
\text { ao se consultar com um farmacêutico; por que o seu vizinho utilizaria ou não } \\
\text { os serviços de um farmacêutico, o seu perfil e descrição dessa pessoa (técnica } \\
\text { projetiva); sentiria-se orgulhoso de ter um filho farmacêutico; como seria o far- } \\
\text { macêutico ideal. }\end{array}$ \\
\hline
\end{tabular}

Fonte: os autores.

Dessa forma, para a coleta de dados primários nessa fase são utilizadas entrevistas em profundidade, com o auxílio de roteiros semiestruturados que foram elaborados para os grupos de stakeholders envolvidos neste estudo.

Na análise das entrevistas foi utilizada a técnica de análise de conteúdo. Bardin (2009) pondera que, enquanto método, a análise de conteúdo deriva dos métodos projetivos e é composta por um conjunto de técnicas de análise das comunicações que 
usa procedimentos sistemáticos e objetivos de descrição do conteúdo das mensagens. Concentra-se na análise de resultados, decorrentes de testes de associação de palavras (estereótipos e conotações) e visa pesquisar os estereótipos sociais espontaneamente partilhados pelos membros de um grupo.

Assim, as categorias de análise (families) foram construídas a partir do direcionamento da pesquisa e dos recorrentes termos, conceitos e construções notadas nas falas da população pesquisada (codes). Estas foram organizadas de acordo com o referencial teórico a partir das dimensões da imagem: dimensão funcional, dimensão simbólica, (c) dimensão cognitiva e, dimensão emocional.

Por fim, buscando-se desenhar uma análise dos dados que atenda aos pressupostos teórico-metodológicos, optou-se por utilizar como ferramentas analíticas a apresentação das grades de análise e de sentenças retiradas das entrevistas realizadas.

A categorização consiste no arranjo dos dados de forma que o pesquisador possa tomar decisões e tirar conclusões, pela construção de um conjunto de categorias descritivas, fundamentadas no referencial teórico. A categorização dos dados permite sua descrição, mas é necessário que extrapole a mera descrição, por um esforço de abstração, ultrapassando os dados, tentando prováveis explicações, configurações e fluxos de causa e efeito (GIL, 2010).

\section{RESULTADOS E ANÁLISES}

A fim de contribuir com o entendimento da análise feita, esta foi dividida em quatro dimensões: dimensão funcional, simbólica, cognitiva e emocional.

A Tabela 1 apresenta a frequência de aparecimento das famílias de categorias das entrevistas realizadas nessa fase do estudo. Por meio desta, avalia-se a relevância das categorias escolhidas, assim como a representatividade de cada uma delas.

Tabela 1 - Frequência das famílias de categorias nas entrevistas

\begin{tabular}{lrr}
\hline \multicolumn{1}{c}{ FAMíLIA DE CATEGORIAS } & TOTAL & PERCENTAGEM \\
\hline Dimensão cognitiva & 188 & 18,2 \\
Dimensão emocional & 80 & 7,8 \\
Dimensão funcional & 429 & 41,6 \\
Dimensão simbólica & 335 & 32,4 \\
Total de palavras analisadas & 1032 & \\
Total de palavras do documento & 11753 & \\
\% do documento analisado & $8,78 \%$ & \\
\hline
\end{tabular}

Fonte: os autores. 
A tabela 1 mostra que a análise de dados utilizou 8,78\% dos dados coletados, assim como apresenta o somatório total de análise de dados, ou seja, a apreciação de 11.753 palavras em todo o corpus de análise.

Os resultados da categorização dos atributos que compõem a imagem do farmacêutico pelos depoimentos dos entrevistados pesquisados mostram que a imagem desse profissional apresenta as seguintes dimensões, em ordem relativa de importância: funcional (41,6\%), simbólica (32,4\%), emocional (7,8\%) e cognitiva (18,2\%).

As palavras mais citadas pelos entrevistados em relação ao profissional farmacêutico foram: medicamento, profissional, farmacêutico, pessoas, farmácia, saúde, médico, paciente, segurança, conhecimento, profissão, orientação, atendimento, cliente, população, bom, responsável, confiança, informação e responsabilidade. Em relação às dimensões da imagem, as palavras (codes) mais citadas pelos respondentes estão descritas no Quadro 2.

Quadro 2 - Palavras mais citadas por definição da imagem

\begin{tabular}{|c|l|}
\hline Dimensões & \multicolumn{1}{c|}{ Palavras citadas (codes) } \\
\hline Funcional & $\begin{array}{l}\text { Profissional, paciente, conhecimento, orientação, atendimento, informação, trabalho, } \\
\text { atuação, serviço, saber, importante, atividades, abordagem, tratamento, atenção, aces- } \\
\text { so, assistência, informações, qualidade, disponível, venda, acessível, postura, promo- } \\
\text { ção, atribuições, prevenção. }\end{array}$ \\
\hline Cognitiva & $\begin{array}{l}\text { Saúde, responsável, confiança, responsabilidade, ajuda, correto, atuação, cuidado, } \\
\text { presença, presente, problema, conveniência, poder, relacionamento, credibilidade, } \\
\text { respeito, acolhimento, consciente, competente, necessidade, risco, entendimento. }\end{array}$ \\
\hline Simbólica & $\begin{array}{l}\text { Farmácia, medicamento, médico, profissão, cliente, população, área, remédio, balcão, } \\
\text { estabelecimento, sociedade, balconista, prescrição, dispensação, ética, receita, equipe, }\end{array}$ \\
\hline Emocional & $\begin{array}{l}\text { Segurança, bondade, dúvidas, alegria, mal, sentimento, doença, alívio, medo, tranqui- } \\
\text { lidade, bem-estar. }\end{array}$ \\
\hline
\end{tabular}

Fonte: os autores.

\subsection{QUESTIONAMENTOS AOS PROFISSIONAIS DA SAÚDE}

Todos os profissionais da Saúde entrevistados já tiveram contato com profissionais farmacêuticos e destacaram vários pontos positivos de sua experiência com esse profissional, principalmente sobre as informações inerentes aos medicamentos que são base de formação do farmacêutico.

Evidenciou-se que o conhecimento do profissional farmacêutico sobre os medicamentos facilita o relacionamento com os demais profissionais da Saúde, os quais 
utilizam desse conhecimento em sua atuação. O trabalho da equipe multidisciplinar de saúde é facilitado com a presença do profissional farmacêutico.

De forma significativa, poucos pontos negativos relacionados ao profissional farmacêutico foram citados pelos profissionais da Saúde, podendo-se destacar apenas um relato de um médico entrevistado que afirmar que “[...] alguns farmacêuticos fazem diagnóstico e vendem medicamentos para o cliente.” (Médico 3, informação verbal).

Esse é um ponto que pode ser percebido em outras entrevistas, pois se verifica que alguns farmacêuticos podem realizar atividades que não são inerentes à sua área de atuação, como a realização de diagnóstico e a prescrição de medicamentos de venda sob prescrição médica. Essas atividades geram uma imagem negativa da profissão de farmacêutico.

Quando questionado aos entrevistados qual a relação existente entre a sua profissão e a do profissional farmacêutico, vários pontos foram levantados, mas houve uma ênfase na necessidade da equipe multidisciplinar de saúde pelo conhecimento inerente aos medicamentos que são indicados pelo farmacêutico. O maior ganho nesse relacionamento é a prestação de serviço ao paciente, que muitas vezes é comum a vários profissionais, e esse paciente pode estar usando medicamentos.

Observou-se que as atividades do profissional farmacêutico têm baixa influência em sua profissão. Para os médicos, a influência existe no diagnóstico e na prescrição de medicamentos nas farmácias, o que não deve ser realizado pelo farmacêutico, com já citado. A enfermeira entrevistada relatou que nas unidades básicas de saúde, o farmacêutico supervisiona técnicos de enfermagem, o que, ressalta, não é coerente, já que esse profissional deve trabalhar com técnicos de farmácia para dispensar medicamentos para a população.

\subsection{DIMENSÃO FUNCIONAL}

Procurou-se identificar os aspectos sublinhados pelos stakeholders relacionados à dimensão funcional da imagem. Os resultados da pesquisa mostram que, para alguns entrevistados, a imagem da profissão de farmacêutico nessa dimensão está relacionada, em geral, a o seu conhecimento sobre medicamentos e à orientação destes para a sociedade.

Além do conhecimento e da orientação, a imagem funcional está relacionada ao atendimento e às informações prestadas pelo profissional na prestação dos serviços. O tratamento e a atenção dispensados ao usuário pela forma de abordagem, qualidade das informações e assistência prestada, também podem gerar uma imagem 
negativa ou positiva da profissão. A disponibilidade e a acessibilidade do profissional em relação ao médico também são elementos que compõem a dimensão funcional da imagem, podendo o farmacêutico trabalhar no cuidado com a saúde, seja na prevenção seja na promoção. Uma imagem negativa pode surgir se um desses elementos não é atendido.

A profissão de farmacêutico possui muito respeito e consideração, pois todos os entrevistados, ao serem questionados, indicariam o trabalho desse profissional a um conhecido. Houve unanimidade nesse ponto, podendo-se destacar:

\footnotetext{
"Indicaria, porque o farmacêutico é uma pessoa especial que mexe com adultos, crianças e idosos, e, qualquer um que precise dos trabalhos dele. Eles são pacientes com as pessoas e são as pessoas mais indicadas para orientar e cuidar. Temos que ter consideração com o farmacêutico.” (usuário 4, informação verbal).
}

Embora tenha respeito e consideração, a profissão de farmacêutico apresentou várias percepções por parte dos entrevistados. Alguns declararam se tratar de uma profissão ainda pouco conhecida e valorizada, mas por sua importância para a sociedade está em um processo de ascensão e reconhecimento, tentando resgatar sua imagem. Diante da opinião de alguns profissionais da saúde, esse fato não acontece somente com a profissão de farmacêutico, mas com a maioria das profissões da área da Saúde, pois para a sociedade somente o médico é visto com referência quando se trata do cuidado com a saúde.

Em relação a esse processo de mudança pelo qual passa a profissão farmacêutica, vários pontos foram relatados como influenciadores para esse fenômeno: o descrédito pelo próprio profissional, vários cursos superiores que oferecem baixa qualificação profissional e a falta de manejo e cuidado com o usuário, que foi muito evidenciado. O aumento considerável de profissionais farmacêuticos que se formam anualmente, pelo elevado número de escolas de Farmácia no Brasil, tem contribuído para desequilibrar a balança de oferta e procura de empregos nesse setor. Dessa forma, mesmo com um piso salarial estipulado por convenção coletiva de trabalho, muitos recém-formados aceitam trabalhar recebendo um valor inferior. Diante dos fatos, há um descrédito da profissão pelos próprios profissionais que trabalham desmotivados, podendo levar a uma falha na prestação de serviços, o que traz como consequência uma percepção negativa para a imagem do farmacêutico pela sociedade.

Esse ponto fica mais claro quando questionado aos entrevistados como eles imaginam que seja o profissional farmacêutico. Este tem um reconhecimento da socie- 
dade, mas para muitos dos entrevistados, ele deveria proporcionar maior atenção ao paciente, sendo um cuidador da saúde considerando que isso pouco acontece atualmente.

O profissional farmacêutico possui diversos significados para os entrevistados, podendo-se destacar a sua importância, competência, necessidade e referência para a saúde pública, a responsabilidade profissional, além do seu amplo conhecimento sobre os medicamentos. Quanto aos aspectos tangíveis sublinhados pelos stakeholders, relacionados à identificação do profissional farmacêutico, os resultados da pesquisa indicaram que a imagem está relacionada à postura, à maneira de se vestir desse profissional e à sua identificação visual. O crachá portado pelo profissional e a vestimenta branca (jaleco) utilizados durante o ambiente de trabalho foram os pontos mais citados, mas placas e quadros com o nome e a imagem do farmacêutico afixados no estabelecimento também são objetos utilizados pelos entrevistados para identificarem o profissional. Quanto à postura como objeto de identificação profissional algumas sentenças foram relevantes para relacionar com a estima e o conhecimento do profissional pela sociedade. A distância criada pelo farmacêutico em relação ao paciente nos estabelecimentos tem levado a uma imagem negativa dessa profissão na visão dos stakeholders.

A qualidade do trabalho do farmacêutico é avaliada pela sua educação, acolhimento, atendimento, disponibilidade e atenção prestada à sociedade, sua atitude enquanto profissional de saúde, postura ética e pelos conhecimentos adquiridos sobre os medicamentos.

Quando foi analisada a imagem negativa do profissional farmacêutico nessa dimensão, foram citados os seguintes fatores que podem contribuir para tal fato: a prescrição de um medicamento errado, a sua ausência no estabelecimento, a falta de conhecimento técnico, a dificuldade de acesso, a irresponsabilidade e o foco no interesse comercial, esquecendo-se da prestação de saúde à sociedade.

A ausência do profissional no estabelecimento é um ponto muito relevante, pois se este não estiver presente ao ser procurado pelo paciente, não haverá prestação de serviços farmacêuticos e, o paciente pode buscar orientação do balconista ou se automedicar. Essa ausência gera uma imagem negativa da profissão. Isso também acontece quando o cliente, ao procurar uma orientação para um tratamento de saúde, recebe uma prescrição farmacêutica com excesso de medicamentos ou sem uma informação devida. O paciente se sente enganado, pois percebe o foco da atuação do profissional muito mais comercial do que um agente cuidador da saúde. Nesse sentido, verifica-se uma grande interação entre o profissional farmacêutico e o usuário do seu serviço, que buscam por profissionais com habilidades e capacidades adequadas para 
atenderem às suas exigências específicas, como pode ser observado nos depoimentos anteriores. Um prejuízo para a imagem dessa profissão pode vir de uma experiência negativa com o usuário, uma vez que a configuração do atendimento é personalizada e, busca satisfazer as necessidades e os desejos de cada cliente.

Verifica-se que a dimensão funcional está mais relacionada à atuação do farmacêutico em farmácias e drogarias pela relação direta com a orientação sobre o uso de medicamentos. Isso demonstra uma visão limitada que muitos possuem das áreas de atuação do farmacêutico.

Em termos teóricos, os resultados são condizentes com o descrito por De Toni, Milan e Schuler (2005) e Stern, Zinkhan e Jaju (2001). Atributos e aspectos tangíveis, bem como diversas atividades desenvolvidas pelos farmacêuticos, foram abordadas pelos respondentes.

\subsection{DIMENSÃO COGNITIVA}

Os resultados evidenciaram que os estudantes, antes de ingressarem no Curso de Farmácia, desconheciam as atribuições do profissional farmacêutico e sua importância como prestador de serviços da saúde.

A presença do farmacêutico no local de trabalho é fundamental, sendo um ponto relevante para a sociedade, principalmente na farmácia, que foi a área mais citada pelos entrevistados, entre as várias em que o farmacêutico pode atuar. A presença desse profissional pode prevenir o uso incorreto dos medicamentos, bem como a aquisição destes de forma incorreta.

Outras áreas de atuação e atividades do farmacêutico foram relatadas, como a farmácia hospitalar, laboratórios, indústria, farmácia de manipulação, gestão do estabelecimento, organização e logística, além do atendimento ao cliente em consultórios, que ainda é pouco divulgado. Entretanto, muitos dos entrevistados relacionam a imagem do farmacêutico a um profissional que trabalha em farmácias e drogarias.

O acolhimento, a abordagem correta no atendimento e a execução das atividades são essenciais na execução das atividades desse profissional. O conhecimento adquirido e a forma de orientar e transmitir essa informação são fundamentais para a sociedade. $\mathrm{O}$ encaminhamento do cliente a um profissional médico, quando o farmacêutico não possui conhecimento sobre a causa, também foi citado por alguns dos entrevistados.

Os serviços farmacêuticos prestados nas farmácias e drogarias também foram citados pelos entrevistados como uma atividade profissional, incluindo as atividades 
clínicas e a prescrição farmacêutica, recentemente regulamentada pelo Conselho Federal de Farmácia, mas ainda pouco conhecida pela sociedade.

Diante dos pontos citados, na percepção dos entrevistados, o farmacêutico realmente executa as atividades de orientar e vender medicamentos, ou seja, a dispensação farmacêutica em farmácias foi a atividade mais lembrada pelos respondentes. Entretanto, para alguns dos entrevistados, a atuação do farmacêutico somente com a intenção de vender medicamentos, deixando de lado o cuidado com a saúde, é um ponto negativo no exercício de sua profissão.

Na farmácia, o farmacêutico também realiza atividades burocráticas relacionadas à legislação e ao gerenciamento do estabelecimento. Essas atividades administrativas executadas atualmente pelo farmacêutico estão afastando o profissional do usuário, pois há uma diminuição do tempo disponível para a orientação aos clientes, prejudicando o serviço prestado à sociedade.

A assistência e o atendimento aos clientes foram citados como as principais atividades a serem desempenhadas pelo farmacêutico, mas não estão sendo realizadas de acordo com a necessidade dos usuários. Falta uma assistência de forma individualizada, o que impede a fidelidade ao profissional pelo cliente, situação que acontecia de forma natural no passado. Uma imagem negativa do profissional pode ser gerada, também, quando o farmacêutico é procurado na farmácia em busca de uma orientação e não é encontrado pelo cliente. A presença com falta de assistência também é percebida como um ponto negativo.

As competências mais importantes que descrevem um bom profissional farmacêutico na opinião dos entrevistados são: conhecimento técnico e atualização contínua, desse conhecimento responsabilidade e compromisso, ética, disponibilidade e vontade de ajudar. A abordagem e o atendimento também foram citados com relevância.

Os resultados descrevem basicamente as atividades, as funções e o nível de conhecimento acerca da profissão por parte dos seus stakeholders. Esse tipo de conhecimento forma as crenças e atitudes e é importante para o processo de avaliação das atividades desenvolvidas por esses profissionais (DE TONI et al., 2011; STERN; ZINKHAN; JAJU, 2001).

\subsection{DIMENSÃO EMOCIONAL}

Conforme os entrevistados, o farmacêutico pode despertar emoções tanto positivas quanto negativas, que variam de acordo com a experiência subjetiva de cada um. No entanto, percebe-se uma tendência maior de emoções positivas no relaciona- 
mento com a profissão de farmacêutico e com o próprio profissional. Os sentimentos positivos que foram despertos no passado são suscitados pelos stakeholders.

Para alguns entrevistados, as emoções positivas referem-se a uma relação consensual, em que o farmacêutico esteja disposto a satisfazer os desejos dos clientes. O bom atendimento das necessidades apresentadas ao profissional, principalmente aquelas relacionadas ao uso do medicamento, também pode despertar emoções positivas nos clientes.

De outro lado, as relações conflituosas são geradoras de emoções negativas, como a ausência no estabelecimento, a forma de atendimento e abordagem, a falta de conhecimentos específicos sobre os medicamentos e, principalmente, a falta de cuidado com o paciente.

Foram avaliados os sentimentos provocados nos entrevistados quando estes se dirigem a um estabelecimento farmacêutico e encontram o profissional farmacêutico. Pode-se destacar a sensação de segurança, credibilidade no estabelecimento, felicidade, confiança, alívio, orgulho, tranquilidade e alegria. Isso evidencia a importância da presença do farmacêutico no estabelecimento, principalmente no atendimento ao usuário.

A falta de ética profissional gera uma imagem negativa da profissão, sendo percebida principalmente quando o usuário se sente enganado pelo farmacêutico, seja pela venda de medicamentos desnecessários seja por um erro na comercialização. A falta de disponibilidade do profissional no atendimento também repercute de forma negativa.

Foi questionado aos entrevistados o que mais oferece prazer quando vão à farmácia. Para a maioria dos entrevistados, o fato de encontrarem o medicamento prescrito por um médico foi os mais citados. Foram poucos os entrevistados que relacionaram o prazer de ir a um estabelecimento com a presença do profissional farmacêutico. O bom atendimento do balconista ou do farmacêutico também tem relevância, assim como os aspectos tangíveis do estabelecimento, o preço e o desconto no medicamento.

Em contrapartida, o sentimento negativo também pode ser apontado pela ausência do farmacêutico nesse estabelecimento, o alto preço dos medicamentos e falha no atendimento.

O acolhimento do paciente pelo farmacêutico é outro ponto a ser analisado. Um bom acolhimento demonstra compromisso e repassa segurança, em contrapartida a falta do acolhimento gera sentimentos opostos. Foi relatado, também, por um dos entrevistados, que o farmacêutico impera uma relação de poder, a qual atrapalha no 
relacionamento. Para outros entrevistados, essa relação tem melhorado, mas o farmacêutico ainda fica um pouco distante.

Dessa forma, observa-se que as emoções contribuem para a formação da avaliação do farmacêutico por parte dos seus stakeholders, geradas principalmente pela sua experiência anterior, positiva ou não. Essa avaliação e consequente formação de imagem estão em consonância com os conceitos teóricos descritos anterioremente (DE TONI; MILAN; SCHULER, 2005; REYNOLDS; GUTMAN, 1984).

\subsection{DIMENSÃO SIMBÓLICA}

Por meio da avaliação da dimensão simbólica da imagem foi possível identificar o que o farmacêutico representa ou significa para os clientes. Apesar de se tratar de uma dimensão bastante subjetiva, foi possível perceber alguns significados comuns aos entrevistados.

Pôde-se constatar nas entrevistas que o cliente associa o profissional farmacêutico com segurança, informação, apoio, confiança, qualidade, acessibilidade, ajuda, cumplicidade, além de comodidade e praticidade.

Para os entrevistados, a procura pelos serviços farmacêuticos em vez da automedicação é avaliada como um ponto muito positivo, mas outros relataram que se o paciente necessita de medicamento, deve procurar o médico e não o farmacêutico. Houve uma divergência na opinião dos entrevistados quanto à procura do paciente pelo farmacêutico. Alguns buscam esse profissional pela segurança no uso dos medicamentos e, outros por conveniência, em geral pela facilidade de acesso e gratuidade dos serviços.

Foi verificado que existem poucas diferenças de percepções entre homens e mulheres em relação ao profissional farmacêutico, mas as mulheres procuram mais informação, apoio e confiança pelo farmacêutico. Foi relatado que as mulheres cuidam mais da saúde por serem mais detalhista cuidadosas e querem mais apoio do farmacêutico que os homens, que são mais sigilosos e acanhados e buscam uma informação direta e rápida. Há uma necessidade diferenciada no atendimento.

Os homens ficam mais constrangidos que as mulheres ao serem atendidos pelo profissional farmacêutico do gênero feminino. Isso não acontece com as mulheres ao serem atendidas por indivíduos de gênero oposto.

Foram levantados os motivos de indivíduos que nunca utilizaram os serviços do farmacêutico, o perfil e a descrição desses indivíduos. Pode-se citar o desconhecimento da profissão de farmacêutico, a insegurança de contatar esse profissional, a 
falta de credibilidade no farmacêutico, a confusão da imagem do farmacêutico com o balconista nas farmácias e o medo de ser atendido por profissionais da Saúde.

A maioria dos entrevistados se sentiria orgulhosa caso seus filhos fossem farmacêuticos. Uma discente de Farmácia, que está quase concluindo o curso, sente-se insegura pela desvalorização da profissão atualmente e não sabe como será no futuro. Outros dois entrevistados não foram favoráveis a essa escolha.

O farmacêutico ideal, para os entrevistados, deve ser ético, atualizado, satisfeito e realizado com a escolha profissional, que cuida do usuário como zelo e responsabilidade sendo acolhedor e dedicado, e preza muito mais pela saúde do usuário do que pela venda do medicamento.

É possível perceber que a dimensão simbólica está relacionada ao significado do farmacêutico para os stakeholders e que, de forma geral, é positivo. Isso é importante para ressaltar a relação entre o indivíduo e o símbolo farmacêutico (STERN; ZINKHAN; JAJU, 2001; DOBNI; ZINKHAN, 1990).

\section{CONCLUSÃO}

Sendo constituída por características físicas percebidas e avaliadas pelos stakeholders durante a prestação de serviços, a dimensão funcional revelou que não há uma imagem específica do profissional farmacêutico quanto aos aspectos tangíveis. Esses elementos representam menor papel, pois a inseparabilidade exerce maior relevância na prestação de serviços pelo farmacêutico. A postura, o conhecimento adquirido e a forma de orientação ao usuário pelo profissional no estabelecimento são muito relevantes na formação dessa imagem.

No que se refere à dimensão cognitiva, os resultados apontam que os stakeholders da profissão de farmacêutico não conseguem ter uma noção clara do que consiste a profissão e nem de suas atribuições. Essa confusão parece iniciar-se no próprio Curso de Farmácia, que não oferece ao aluno uma visão abrangente de suas possibilidades de atuação. Existe baixo conhecimento sobre as possibilidades de atuação do farmacêutico, limitando-se, basicamente, às áreas de Farmácia e Drogaria, principalmente em relação ao medicamento.

A percepção da presença desse profissional de forma atuante nesses estabelecimentos é vista como muito positiva, com um foco no atendimento e orientação ao usuário sobre o uso correto dos medicamentos. Dessa forma, a ausência do farmacêutico ou a falta de assistência ao usuário gera uma imagem negativa da profissão. 
A prescrição farmacêutica, se realizada somente com interesse comercial, também leva a uma imagem negativa da profissão. Acredita-se que esse baixo conhecimento sobre a profissão possa estar interferindo negativamente na percepção de valor dos serviços prestados por essa categoria profissional.

A dimensão emocional da imagem do farmacêutico diz respeito às emoções evocadas antes, durante e após a prestação de um serviço, e foi observado que esse profissional é capaz de despertar tanto emoções positivas quanto negativas, havendo, entretanto, uma predominância de relatos de emoções positivas. Tais emoções relacionam-se tanto ao processo da prestação de serviço (amor, alegria, segurança, gratidão, felicidade) quanto aos resultados atingidos por meio dele (bem-estar, melhora, tranquilidade, cura).

A avaliação da dimensão simbólica, que demonstra as representações e significados do serviço para os stakeholders, mostrou que a profissão de farmacêutico tem como significados mais relevantes: “ajuda, apoio e cumplicidade”, que são representações extremamente emotivas e assistencialistas, "segurança, confiança, informação e qualidade”, que remetem ao profissional como uma fonte segura e confiável de informação e “acessibilidade, comodidade e praticidade”, que podem ser aproveitadas pelo profissional para apresentação e prestação dos serviços.

Comparando-se os resultados com os de outros estudos, é possível descrever que, no caso dos psicólogos (MENDES, 2008), é necessário um maior conhecimento sobre as necessidades dos seus clientes em termos das suas necessidades, bem como dos outros stakeholders. Apesar do contato intenso com os clientes, alguns percebem uma distância entre a técnica e o conhecimento do mercado por parte dos psicólogos. Em relação aos arquitetos (GRASSELI, 2007), foi identificada grande insatisfação por parte dos profissionais da área, o que colabora para uma imagem relativamente desvalorizada por parte dos profissionais. No caso dos funcionários públicos de um tribunal de justiça (AQUINO; TEIXEIRA; ANDRADE, 2012) a dimensão da imagem mais proeminente foi a dimensão funcional, em virtude das atividades que os funcionários executavam. A imagem é positiva para os stakeholders em geral, excetuando-se os jovens advogados que possuíam uma imagem mais negativa desses funcionários.

Em termos práticos, a compreensão da imagem do profissional farmacêutico sob o prisma dos stakeholders pode oferecer contribuições para a formulação e implementação de estratégias (por exemplo, comunicação à sociedade, valorização profissional e orientação aos profissionais) para a profissão, importantes para o direcionamento estratégico. A melhoria da percepção da imagem perpassa dois aspectos importantes: a comunicação e o relacionamento entre o farmacêutico e os cidadãos. 
Dessa forma, por meio de orientação, treinamento e palestras, os profissionais terão as informações pertinentes para agirem de forma técnica, mas também agindo de forma a criar relacionamentos mais efetivos aos anseios da sociedade. Além disso, informações acerca - por exemplo - das diversas atividades realizadas por esse profissional devem estar disponíveis para a população em geral.

Em termos acadêmicos e teóricos, uma sugestão de trabalho futuro baseia-se na construção de uma escala - e consequentemente sua validação e teste - considerando as quatro dimensões (funcional, cognitiva, emocional e simbólica) formadoras da imagem. A nova escala em termos práticos pode ser útil para os representantes dessa categoria profissional, como um instrumento para o acompanhamento, controle e gerenciamento da percepção da imagem dos farmacêuticos pelos próprios profissionais e também pela sociedade em geral.

Por fim, esta é uma pesquisa exploratória de abordagem qualitativa e, assim, os seus resultados não podem ser generalizados. É importante ressaltar, ainda, as características da amostra, as quais também limitam a generalização dos resultados, como o seu tamanho e o seu processo de amostragem por conveniência.

\section{REFERÊNCIAS}

AAKER, J. L. Dimensions of brand personality. Journal of Marketing Research, v. 34, i. 3, p. 347-356, 1997.

AMORIM, A. A. Marketing de Serviços: um estudo exploratório sobre a imagem e a identidade da Fisioterapia. 2009. Dissertação (Mestrado em Administração)-Universidade Fumec, Belo Horizonte, 2009.

AQUINO, J. M. C. de; TEIXEIRA, L. A. A.; ANDRADE, D. F. Identificação e imagem do servidor público: um estudo com os usuários do Tribunal de Justiça do Estado de Minas Gerais. In: ENCONTRO DE ADMINISTRAÇÃO PÚBLICA E DE GOVERNO (ENAPG), 5., 2012, Salvador. Anais... Salvador, 2012.

AREOSA, J.; CARAPINHEIRO, G. Quando a imagem é profissão: profissões da imagiologia em contexto hospitalar. Sociologia, Problemas e Práticas, v. 57, p. 83108, 2008.

BARDIN, L. Análise de conteúdo. Lisboa: Edições, 70, 2009.

BARICH, H.; KOTLER, P. A framework for marketing image management. Sloan Management Review, v. 32, i. 2, p. 94-104, 1991. 
CONSELHO FEDERAL DE FARMÁCIA. Áreas de atuação da Profissão Farmacêutica. Brasília, DF, 2013. Disponível em: <http://www.cff.org.br/pagina. php?id=87\&titulo=\%C3\%81reas+de+atua\%C3\%A7\%C3\%A3o $>$. Acesso em: 09 jan. 2014.

DE TONI, D. Administração da imagem de organizações, marcas e produtos. In: KUNSCH, M. M. K. (Org.). Comunicação organizacional. São Paulo: Saraiva, 2009. v. 1.

DE TONI, D. et al. A imagem do comércio varejista e a satisfação dos consumidores: um estudo exploratório ambientado em uma cidade da Serra Gaúcha. Revista Base, v. 8, n. 1, p. 91-104, 2011.

DE TONI, D.; MILAN, G. S.; SCHULER, M. Configuração de imagens de serviços: um estudo aplicado aos serviços de fisioterapia disponibilizados por um plano de saúde. In: ENCONTRO NACIONAL DOS PROGRAMAS DE PÓS-GRADUAÇÃO EM ADMINISTRAÇÃO, 29., 2005, Curitiba. Anais... Curitiba, 2005.

DE TONI, D.; MILAN, G. S.; SCHULER, M. Gestão de imagem: desenvolvendo um instrumento para a configuração da imagem de produto. In: ENCONTRO NACIONAL DOS PROGRAMAS DE PÓS-GRADUAÇÃO EM ADMINISTRAÇÃO, 38., 2004, Curitiba. Anais... Curitiba, 2004.

DICHTER, E. What's in an image? The Journal of Consumer Marketing, v. 2, i. 1, p. 75-81, 1985.

DOBNI, D.; ZINKHAN, G. M. In search of brand image: foundation analysis. Advances in Consumer Research, v. 17, i. 1, p. 110-119, 1990.

FARINA, S. S.; ROMANO-LIEBER, N. S. Atenção farmacêutica em farmácias e drogarias: existe um processo de mudança? Saúde Sociedade, v. 18, n. 1, p. 7-18, 2009.

FINN, A.; LOUVIERE, J. J. Shopping center image, consideration, and choice: anchor store contribution. Journal of Business Research, v. 35, i. 3, p. 241-251, 1996.

FRANCESCHET, I. Análise das atividades realizadas pelos farmacêuticos no serviço de farmácia pública no município de florianópolis, SC. 2003. Dissertação (Mestrado em Administração)-Universidade Federal de Santa Catarina, Florianópolis, 2003. 
GARDNER, B. B. E.; LEVY, S. J. The product and the brand. Harvard Business Review, v. 33, i. 2, p. 33-39, 1955.

GASPARIN, F. M. A Configuração da imagem de um shopping center na percepção de consumidores locais. 2011. Dissertação (Mestrado em Administração) Universidade de Caxias do Sul, Caxias do Sul, 2011.

GIL, A. C. Métodos e técnicas de pesquisa social. São Paulo: Atlas, 2010.

GOSS, J. The magic of mall: an analysis of form, function and meaning in the contemporary retail built environment. Annuals of the Association of American Geographers, v. 83, i. 1, p. 18-47, 2010.

GRASSELI, M. Marketing na Arquitetura: um hiato entre a imagem e a identidade profissional. 2007. Dissertação (Mestrado em Administração)Universidade Fundação Mineira de Educação e Cultura, Belo Horizonte, 2007.

IBARRA, H. Provisional selves: Experimenting with image and identity in professional adaptation. Administrative Science Quarterly, v. 44, i. 4, p. 764-791, 1999.

ITALIANI, F. Marketing farmacêutico. Rio de Janeiro: Qualitymark, 2006.

JOHNSON, M.; ZINKHAN, M. G. Defining and measuring company image. In: ANNUAL CONFERENCE OF THE ACADEMY OF MARKETING SCIENCE, 13., 1990, New Orleans. Anais... New Orleans, 1990.

JOLY, M. Introdução à análise da imagem. São Paulo: Papirus, 2003.

KUNSCH, M. M. K. Planejamento de Relações Públicas na Comunicação Integrada. São Paulo: Summus, 2003.

LEVY, S. J. Symbols for sale. Harvard Business Review, v. 37, i. 4, p. 117-129, 1959.

LINDQVIST, J. D. Meaning of image: a survey of empirical and hypothetical evidence. Journal of Retailing, v. 50, i. 4, p. 29-38, 1974.

MACHADO, A. J. Imagem do programa de orientação e proteção ao consumidor: um estudo sobre as percepções de consumidores, advogados e representantes de procons e empresas do segmento financeiro. 2010. Dissertação (Mestrado em Administração)-Universidade Fundação Mineira de Educação e Cultura, Belo Horizonte, 2010. 
MALHOTRA, N. K. Pesquisa de Marketing: uma orientação aplicada. Porto Alegre: Bookman, 2011.

MARTINEAU, P. The personality of retail store. Harvard Business Review, v. 36, i. 1, p. 47-55, 1958.

MAY, E. G. Pratical Applications of Recent Retail Image Research. Journal of Retailing, v. 50, i. 4, p. 15-20, 1974.

MENDES, R. L. Marketing na psicologia: um estudo exploratório sobre a imagem profissional. 2008. Dissertação (Mestrado em Administração)-Universidade Fundação Mineira de Educação e Cultura, Belo Horizonte, 2008.

MILAN, G. S.; DE TONI, D.; BARAZETTI, L. Configuração e organização de imagens de serviços: um estudo exploratório. Revista Produção, v. 15, n. 1, p. 60-73, 2005.

MOSCOVICI, S. Social Representation: explorations in social psychology. Cambridge: Polity Press, 2000.

REYNOLDS, T. J.; GUTMAN, J. Advertising is image management. Journal of Adverstising Research, v. 24, i. 1, p. 24-36, 1984.

REYNOLDS, W. H. The role of the consumer in image building. California Management Review, v. 7, i. 3, p. 69-76, 1965.

ROBERTS, L. M. Changing faces: professional image construction in diverse organizations. In: ACADEMY OF MANAGEMENT, 63., 2003, Seattle. Anais... Seattle, 2003.

SCATENA, L. S. Sustentabilidade, responsabilidade social, ética e princípios da precaução - um estudo sobre o ambientalismo corporativo na indústria farmacêutica. 2012. Dissertação (Mestrado em Administração)-Universidade de São Paulo, São Paulo, 2012.

STERN, B.; ZINKHAN, G.; JAJU, A. Marketing images: construct definition, measurement issue, and theory development. Marketing Theory, v. 1, i. 2, p. 201-224, 2001.

TAVARES, M. C. A Força da marca. São Paulo: Harbra, 1998. 
VERGARA, S. C. Projetos e relatórios de pesquisa em administração. São Paulo: Atlas, 2013.

VICTER, P. P. Marketing no turismo: um estudo descritivo sobre a imagem do intercâmbio de cursos de idiomas. 2009. Dissertação (Mestrado em Administração)-Universidade Fundação Mineira de Educação e Cultura. Belo Horizonte, 2009.

VOUGH, H. et al. What Clients Don't Get About My Profession: A Model of Perceived Role-Based Image Discrepancies. Academy of Management Journal, v. 56, i. 4, p. 1050-1080, 2013.

Como citar este artigo:

ABNT

FERREIRA, Luis Claudynei; MOURA, Luiz Rodrigo Cunha; SOUKI, Gustavo Quiroga. A imagem profissional: um estudo sobre o farmacêutico. RACE, Revista de Administração, Contabilidade e Economia, Joaçaba: Ed. Unoesc, v. 15, n. 2, p. 1007-1034, set./dez. 2016. Disponível em: <http://editora.unoesc.edu.br/index.php/ race $>$. Acesso em: dia/mês/ano.

APA

Ferreira, L. C., Moura, L. R. C., \& Souki, G. Q. (2016). A imagem profissional: um estudo sobre o farmacêutico. RACE, Revista de Administração, Contabilidade e Economia, 15(2), 1007-1034. Recuperado em dia/mês/ano, de http://editora.unoesc. edu.br/index.php/race 
